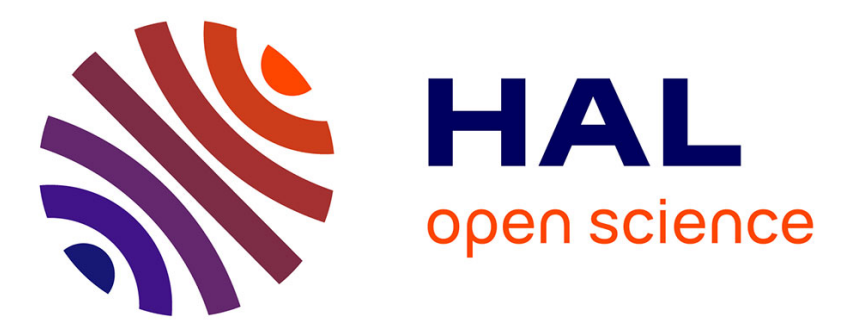

\title{
Ages and stages questionnaires: Feasibility of postal surveys for child follow-up
}

Pénélope Troude, Jane Squires, Laurence Foix L'Helias, Jean Bouyer, Elise de La Rochebrochard

\section{- To cite this version:}

Pénélope Troude, Jane Squires, Laurence Foix L'Helias, Jean Bouyer, Elise de La Rochebrochard. Ages and stages questionnaires: Feasibility of postal surveys for child follow-up. Early Human Development, 2011, 87 (10), pp.671-676. 10.1016/j.earlhumdev.2011.05.007 . hal-02265990

\section{HAL Id: hal-02265990 \\ https://hal.science/hal-02265990}

Submitted on 13 Aug 2019

HAL is a multi-disciplinary open access archive for the deposit and dissemination of scientific research documents, whether they are published or not. The documents may come from teaching and research institutions in France or abroad, or from public or private research centers.
L'archive ouverte pluridisciplinaire HAL, est destinée au dépôt et à la diffusion de documents scientifiques de niveau recherche, publiés ou non, émanant des établissements d'enseignement et de recherche français ou étrangers, des laboratoires publics ou privés. 
Troude Pénélope, Squires Jane, Foix-L’Hélias Laurence, Bouyer Jean, La Rochebrochard Elise (de), 2011, “Ages and stages questionnaires: Feasibility of postal surveys for child follow-up", Early Human Development, 87(10), p. 671-676. DOI: 10.1016/j.earlhumdev.2011.05.007.

\title{
Ages and Stages Questionnaires: feasibility of postal survey for child follow-up
}

\author{
Pénélope Troude ${ }^{\text {a,b,c,* }}$, JaneSquires ${ }^{d}$, Laurence Foix L'Hélias e,f,g, \\ Jean Bouyer ${ }^{\text {a,b,c }}$, Elise de La Rochebrochard ${ }^{\text {a,b,c }}$
}
a. Ined, F-75020 Paris, France
b. Inserm CESP U1018, F-94276 Le Kremlin-Bicêtre, France
c. Univ Paris-Sud, UMRS 1018, F-94276 Le Kremlin-Bicêtre, France
d. Center on Human Development, University of Oregon, USA
e. Inserm U953, 82 avenue Denfert-Rochereau, F-75014 Paris, France
f. Univ Pierre et Marie Curie-Paris 6, F-75252 Paris, France
g. Service de Pédiatrie et Réanimation Néonatales, Hôpital Universitaire Antoine Béclère, F-92141 Clamart, France

Conflict of interest statement: Except Jane Squires, who is one of the authors of the ASQ, no other authors have any conflict of interest. 


\begin{abstract}
Background: The Ages and Stages Questionnaire (ASQ), completed by parents and caregivers, has been shown to be an accurate tool for screening children who need further developmental assessment.
\end{abstract}

Aims: to assess the feasibility of using the French Canadian translation of the ASQ in an epidemiological cohort of children from the French general population.

Study design: follow-up study by postal questionnaire at 12 and 36 months, using the ASQ. Subjects: 339 French families recruited at the birth of their child in 2006 in two hospitals in the Paris suburbs.

Outcome measure: response rates and French ASQ results at 12 and 36 months. The ASQ was scored as indicated in the manual.

Results: A high response rate of $79 \%$ was observed at the children's 1 st and 3rd birthdays. Parents were enthusiastic about participating; half of them wrote comments on the questionnaires, most of them positive. Low scores at the 12-month assessment were associated with birth characteristics such as prematurity and transfer to the neonatology unit after birth, whereas at 36 months they tended to be associated with both birth and family socio-demographic characteristics.

Conclusions: Use of the French ASQ in a research cohort appears feasible as response rates were high. Moreover, known links between child development measured by ASQ and birth and social characteristics were observed. However, further French studies are needed to understand differences observed in 12-month ASQ gross motor scores compared with US norms. For research purposes, further analysis of the ASQ in innovative, quantitative approaches, is needed. 


\section{INTRODUCTION}

Follow-up of large cohorts of children requires a reliable method of evaluating children's development at a low individual cost. It would indeed be too costly to have each child examined individually by a professional. One possibility is to question parents directly about their infant's behavior; however, no specific tool has been validated for child development monitoring in research cohorts. Various parent-completed questionnaires have been developed in the last twenty years to screen children who need further investigation by a medical professional. The Parents' Evaluation of Developmental Status (PEDS), the Child Development Inventories (CDI) and the Ages and Stages Questionnaires (ASQ) are described by the American Academy of Pediatrics as very good instruments with excellent psychometric properties (1). Moreover, they are increasingly used by physicians in clinical practice for the screening of developmental delay (2-5). Thus, one possible way of monitoring child development in a large research cohort could be to use a parent-completed questionnaire (6).

The ASQ screening system was developed by the University of Oregon's Center on Human Development during the 1980s and 1990s in response to a growing need for early and accurate identification of children who have developmental delays or disorders (7). The ASQ screening system has been validated in multiple languages, including French Canadian. This system was developed to be used originally in a mail-out format. The original ASQ screening system is composed of 19 questionnaires that span the age range of 4 months to 60 months (5 years) and are designed to be completed by parents or primary caregivers (1999 version); the newly revised $3^{\text {rd }}$ edition consists of 21 questionnaires covering the 2-66 month age span (2009 version). Parents are asked to attempt every activity with their child, and to try again later if their child is noncompliant. Each questionnaire consists of 30 items that give equal cover to 5 areas: communication, gross motor, fine motor, problem solving and personal- 
social. For each developmental item, three responses are possible depending on how the child performs the behavior specified in the item: "yes" (10 points), "sometimes" (5 points) and "not yet" (0 points). For each area, the total score is obtained by adding the scores of the 6 items and cut-offs have been defined for each area (2 SD or less below the mean score). When the child does not pass at least one area (i.e. score under the cut-off), a consultation with a medical professional for further investigation is indicated. The ASQ system is used in clinical practice but clinicians tend to refer for specialized consultation only those children who do not pass at least two areas (5). This decreases the sensitivity of the ASQ screening but increases its specificity. Such an approach, with better balance between sensitivity and specificity, could be preferentially used when medical resources are scarce or when the objective is not clinical screening but research, as in the follow-up of large cohorts of children.

The psychometric properties of the ASQ have been studied by the authors (7) and by others in different countries (8-12). In terms of reliability, internal consistency of correlations between area and overall score ranged from 0.70 to 0.83 for both the 12 -month and the 36month ASQ intervals. The percentage of agreement between two questionnaires completed by parents at a 2-week interval was used to assess test-retest reliability and was $94 \%(n=175)$. Inter-observer reliability, measured as the percentage of agreement between results of the questionnaire completed by parents and results of those completed by two examiners, was 94\% ( $\mathrm{n}=112)$. Questionnaire validity has been studied using various professionally administered standardized developmental tests such as the Revised Gesell and Amatruda Developmental and Neurological Examination and the Bayley Scales of Infant Development. For the 12 and 36-month ASQ, sensitivity ranged from $70 \%$ to $90 \%$ and specificity from $83 \%$ to $91 \%$ (7). Other studies in general populations, as well as in at-risk populations, have 
confirmed good psychometric properties for the ASQ, with reported sensitivity that ranged from $67 \%$ to $100 \%$ and specificity from $76 \%$ to $100 \%(8-12)$.

The aim of our study was to assess the feasibility of using the French Canadian translation of the ASQ in an epidemiological cohort of children from the French general population (6). Children were followed up at 12 and 36 months. We also aimed to explore the association of ASQ results with health characteristics at birth, and with socio-economic characteristics of parents. 


\section{PATIENTS AND METHODS}

\section{STUDY POPULATION}

Families were recruited at the child's birth, between January 1 and February 4, 2006, in two maternity hospitals in the suburbs of Paris, France (13). The research protocol included recruitment of all women giving birth during this period. A follow-up study concerning children's activities was proposed to the 339 mothers who responded to the birth questionnaire, who accepted the follow-up and had a valid address. The study was approved by the French Data Protection Authority (CNIL; authorization number 05-1335, 905304 versions 1 and 3).

\section{PROCEDURE}

The postal survey took place between January and February 2007 for the 12-month ASQ and between January and February 2009 for the 36-month ASQ. After two or three weeks, a reminder letter was sent to those who had not replied and two to three weeks later, a duplicate postal ASQ questionnaire was again sent to those who had not yet replied. One year after the survey, the parents received a newsletter presenting the final results of the study. Postal addresses were updated annually. For parents whose child did not pass several areas of the ASQ and who did not state that the child was receiving medical follow-up, a brief letter was enclosed with the results of the study, containing an invitation to consult a pediatrician and giving the contact details of the pediatrician of the maternity department where the parents had been recruited. 


\section{MEASURES}

The $1^{\text {st }}$ and $3^{\text {rd }}$ birthday questionnaires included items on parents' socio-demographic characteristics as well as the ASQ 12 or 36-month questionnaires (second edition, French Canadian translation). Information on newborn health status was extracted from the medical record during the birth survey (birth weight, sex, gestational age and transfer to neonatology unit). Information on the parents' socio-demographic characteristics was available from the birth questionnaire filled out by the mother six weeks after the birth (age, nationality, level of education). Information on income was approached by a question on perception of financial situation that has been shown to be relevant $(14,15)$. At the end of the 12 and 36-month questionnaires, parents were asked whether they had completed the parent-child activities specified on the ASQ. They were also asked if their child was willing or unwilling to perform these activities. Questionnaires were scored by the research team as indicated in the ASQ user's guide (7). Questionnaires completed outside the 2-month window of administration were not included in the sample.

As our aim was to evaluate child development in a research cohort and not to clinically screen development, we defined at-risk children as those with two areas under the suggested cut-off scores in order to achieve a better balance between sensitivity and specificity. In multiple pregnancies $(n=9)$, only the first-born of the twins or triplets was included in the analyses to satisfy the independence assumption.

\section{STATISTICAL ANALYSIS}

Response rates and usable questionnaire rates were tabulated for each phase. To explore potential selection bias, factors associated with response rate were investigated using the chisquare test or Fisher's exact test. 
We recorded the percentage of children who did not pass the ASQ at 12 and at 36 months. Area mean scores were compared with reference mean scores published in the ASQ User's Guide for the Ages and Stages Questionnaires (1999) (Student's t test) (7).

Associations between the child's failure in at least two areas, neonatal characteristics and parents' socio-demographic factors were investigated for the 12-month and the 36-month ASQ using logistic regression. The following neonatal characteristics were studied: sex, birth weight (low birth weight i.e. $<2500 \mathrm{~g}$ vs $\geq 2500 \mathrm{~g}$ ), gestational age (premature i.e. $<37 \mathrm{WA}$ vs $\geq 37$ WA), and newborn transfer to neonatology unit (yes vs no). As development is known to be linked to the child's socioeconomic environment, the following parental characteristics were also studied: mother's and father's age at the birth of the child $(<35$ years vs $\geq 35$ years), mother's and father's educational level ( $>$ or $\leq 2$ years after high school diploma), parents' nationality (French vs other), family situation (parents living together vs parents separated), mother's occupational status (mother working at the child's $1^{\text {st }}$ or $3^{\text {rd }}$ birthday vs not working), and smoking during pregnancy (yes vs no).

Variables included in the multivariate models were selected by a backward stepwise procedure with a significance level for removal from the model of 0.20 .

We also investigated correlations between 12-month and 36-month ASQ results with the Pearson correlation coefficient.

All statistical analyses were performed using STAT/SE 10.0 (Stata Press, College Station, TX, USA). 


\section{RESULTS}

Participation figures in the two phases of the study are presented in Figure 1 . For the $1^{\text {st }}$ and $3^{\text {rd }}$ birthday assessments, $79 \%$ of mothers responded to the postal questionnaire $(268 / 339$ and 205/260). Among the questionnaires returned, 85\% (12 months: 229/268) and 87\% (36 months: 179/205) were usable. The main reason for exclusion of questionnaires was delay in response, leading the child to fall outside the "age window" for valid scoring (74\%). Missing dates of questionnaire completion, meaning that the child's exact age at completion was not known, accounted for $14 \%$ of excluded questionnaires, while missing answers on the ASQ making it impossible to calculate the score accounted for $12 \%$ of excluded questionnaires. Finally, 265 families that completed a usable 12 and/or 36-month ASQ questionnaire were included. Both the 12 and 36-month questionnaires were completed and usable by 143 families (229-143=86 families had only the 12-month ASQ questionnaire completed and usable and 179-143=36 families had only the 36-month ASQ questionnaire completed and usable).

Characteristics of the study population are presented in Table $2(n=265)$. The mother's median age at the child's birth was 32 years and the father's was 33 years. About $60 \%$ of mothers and $50 \%$ of fathers had completed at least 2 years of education beyond the high school diploma, and $71 \%$ of couples reported that their financial situation was "comfortable" or "fair". At the child's $1^{\text {st }}$ birthday, $70 \%$ of mothers worked outside the home whereas $79 \%$ worked outside the home on the child's $3^{\text {rd }}$ birthday. Concerning the child, $8 \%$ had a birth weight lower than $2500 \mathrm{~g}$ and $9 \%$ were premature.

Detailed results of the 12 and 36-month ASQ are presented in Table 3. Of the 22912 month ASQs, $14 \%$ of the infants did not pass at least two areas. The area most often failed was gross motor (26.6\%), followed by communication (17.9\%) and problem solving (12.7\%). 
All area mean scores in our study were significantly lower than the reference mean scores. The mean total score was 197.3 ( $\mathrm{SD}=51.3$ ). Of the 179 36-month ASQs, 7\% of children did not pass at least two areas. The area that children most often failed was fine motor $(11.7 \%)$, whereas less than $7 \%$ of children failed all other areas. Mean scores did not significantly differ from reference mean scores for communication and gross motor areas but were significantly lower for fine motor, problem resolution and personal-social areas. The mean total score was $257.6(\mathrm{SD}=36.8)$.

Factors associated with failure in the 12 and the 36-month ASQ are presented in Table 3. Twelve-month ASQ results were associated with the child's health at birth (prematurity and transfer to neonatology unit after birth). Neither the mother's nor the father's educational levels were associated at 12 months, but the mother's educational level tended to be associated with the 36-month ASQ results $(\mathrm{p}=0.06)$. The proportion of children living in a single-parent family (mainly the mother) was nearly two-fold higher among children who did not pass the questionnaires, but this did not reach statistical significance. In multivariate analysis (data not shown), for the 12-month ASQ only prematurity remained associated with ASQ failure with an odds ratio of $4.6(95 \%$ CI [1.7-12.3], $\mathrm{p}=0.002)$ but single-parent families tended to be associated with ASQ failure with an odds ratio of 3.4 (95\% CI [0.8-14.4], $\mathrm{p}=0.09$ ). At 36 months, ASQ failure was associated with a low level of maternal education $(\mathrm{OR}=0.2,95 \% \mathrm{CI}[0.05-0.9], \mathrm{p}=0.03)$ and tended to be associated with the newborn's transfer to a neonatology unit $(\mathrm{OR}=3.7,95 \% \mathrm{CI}[0.8-16.1], \mathrm{p}=0.09)$.

Among the 143 children with a usable questionnaire at 12 and 36 months, the correlation between the 12 and the 36-month ASQ total scores was $0.62(\mathrm{p}<0.01)$. Of the 18 children who did not pass the 12-month ASQ and whose parents completed the 36-month ASQ, 72\% passed at 36 months. Of the 125 children who passed the 12-month ASQ and had 36-month results, 5\% did not pass the 36-month questionnaire. Finally, among the 143 children with 12 
and 36-month results, only 5 (3\%) did not pass both questionnaires. Of these children, 3 failed the same areas at 12 months and 36 months.

To explore potential selection bias in our sample, response rates were studied according to family characteristics and, for the 36-month questionnaire, they were also studied according to the results of the 12-month ASQ. The proportion of respondents did not significantly differ according to the mother's educational level, and none of the child's characteristics at birth were associated with response rate for either of the two study phases (data not shown). Moreover, response rates to the 36-month ASQ were not associated with the results of the 12month ASQ. In the group of children who did not pass the 12-month ASQ, 75\% of their parents responded to the 36-month ASQ, and among children who passed the 12-month ASQ, $85 \%$ of parents responded $(\mathrm{p}=0.17)$. There were also no differences in the percentage of usable 36-month ASQs according to the result of the 12-month ASQ (86\% vs. 90\%, $\mathrm{p}=0.56$ ). 


\section{DISCUSSION}

Based on our results, using the ASQ as a means of assessing child development in an epidemiological cohort research study appears feasible. Response rates by parents at both ASQ intervals were high: $79 \%$ of parents answered the postal questionnaire. For both

intervals, more than $96 \%$ of parents agreed to be contacted for a future step, and $98 \%$ wished to receive the overall results of the study. Parents' participation was high and parents were enthusiastic about participating in the study: half of them wrote comments on the questionnaires, most of them positive. These results are in agreement with two Canadian studies in which 88 to $100 \%$ of parents found that ASQ questionnaires were easy to complete $(11,16)$. We found that over $85 \%$ of the questionnaires returned were usable. This result is close to that of a Canadian study in which $22 \%$ of the 18 -month ASQs were returned late (16) and had to be excluded. This rate could probably be improved by emphasizing in the covering letter the need to answer quickly.

The high response rate for both phases of the study may be linked to the study population characteristics. Our population had an educational level higher than the general population, as $82 \%$ of mothers had an educational level equal to or higher than the high school diploma, whereas in France, in the general population, 43\% of pregnant women have reached this level (17). Moreover, a large proportion of couples reported a good financial situation and thus may have fewer financial worries than the general population. The response rate could be lower in a less educated population. However, our study population did not appear to suffer from selection bias, as the proportion of respondents did not significantly differ according to maternal educational level.

We explored associations between ASQ results and the child's health characteristics at birth and found confirmatory results. The known association between premature birth and child development was confirmed by our findings (4, 12, 18-20). Maternal educational level 
was also associated with child developmental outcome as has been shown in the literature (12, 21). In our study, the effect of the child's health at birth on ASQ results seemed to decrease at the 36-month assessment, and the mother's educational level was associated with ASQ results only for the 36-month assessment. Our observations suggest that the effect of the child's health characteristics at birth decrease as his or her age increases, whereas the effect of environmental factors increases. These conclusions are in agreement with the literature (22, 23).

The 2-month age administration window on the $2^{\text {nd }}$ edition of the ASQ appears quite large, as 11 and 13-month-old children may have quite different levels of development. We thus checked our results by restricting our analysis to questionnaires completed for infants aged 12 months or older, and for children of 36 months or older. Among the restricted sample of 116 children aged 12 to 13 months, $14 \%$ did not pass the ASQ (data not shown) which was exactly the same proportion as in the entire sample including 229 children aged 11 to 13 months. Among the restricted sample of 60 children aged 36 to 37 months, $8 \%$ did not pass the ASQ (data not shown) which was very close to the $7 \%$ observed in the entire sample including 179 children aged 35 to 37 months. Moreover, for the 12-month ASQ, among the restricted sample of 116 children aged 12 to 13 months, $26 \%$ of children did not pass the gross motor area and $18 \%$ did not pass the communication area. These proportions were nearly identical to those observed in the entire sample of 229 children aged 11 to $13(27 \%$ and $18 \%$, respectively). The results obtained in older children were thus similar to those of the whole sample. This is a reassuring observation concerning the validity of the ASQ age windows.

Concerning ASQ results at 36 months, we found that mean scores were significantly lower than reference mean scores for three areas (fine motor, problem solving and personal-social), whereas studies in other countries did not find these differences $(7,10,24)$. However, except 
for the fine motor area, the proportion of children that failed each area remained lower than 8\%. At 12 months, all observed mean scores in our study were significantly lower than reference mean scores. Moreover, we observed a greater variability, with higher SDs for almost all areas, in particular for the area that showed the most failures: gross motor (21.3 vs. 15.3) (7). This result differs from other studies, since a Korean study found no differences and a Norwegian study found only two mean scores higher than reference scores, both of them with similar SDs $(10,24)$. The proportion of children $(14 \%)$ who did not pass at least two ASQ areas at 12 months in our sample is too high to be clinically realistic and should not be interpreted as a category of children with developmental problems. In addition, the children of our sample no longer showed such low developmental results at 36 months (the proportion decreased from $14 \%$ to $7 \%$ ). These results suggest there is a need for additional reliability measures of the 12-month cut-off points in the French population. There could be several explanations for this high proportion of failure at 12 months, which we discuss in the following paragraphs.

The second most failed area at 12 months in our study was communication, with $18 \%$ of infants failing this area. In the $3^{\text {rd }}$ edition of the ASQ, the hardest item of the communication area at 12 months has been replaced by an expressive item that is supposed to be achieved earlier (25). When we recalculated our data and considered this item as missing, the proportion of infants who failed the communication area was $15 \%$ and when it was considered as a pass, this proportion fell to $6 \%$. In this case, the communication mean score was 40.9 (SD 14.7) and did not significantly differ from the reference mean score of the second edition $(\mathrm{p}=0.23)$.

In our French population, we observed a high level of failure for the gross motor area at 12 months. However, at 36 months, the proportion of failure for the gross motor area decreased sharply from $26.6 \%$ to $4.5 \%$, suggesting that the 12 -month results did not reflect a true gross 
motor problem. The 12-month gross motor result could be linked to cultural differences in motor milestone achievement, especially the age of walking (26-28). Neither biological nor socioeconomic factors entirely explain these differences, and parental expectations and child rearing practices (effect of first birth order, for instance) probably also play a part in these variations $(29,30)$. The high level of failure for the 12-month gross motor area could also be related to a "seasonal birth period effect". All children of the sample were in fact born in winter. In these children, motor development at 12 months might be slightly delayed because of movement being hampered by winter clothing and less opportunity to go outside during the winter season. Such a "seasonal birth period effect" would concord with the fact that gross motor development no longer appeared delayed at 36 months. Various effects have already been reported in the literature $(10,30)$ that could explain delay in milestone achievement linked to cultural rearing practices. The "seasonal birth period effect" may also need to be taken into account and would require further investigation. In particular, other studies among French children born at various periods of the year would be required in order to compare their gross motor development.

Differences between area mean scores and reference scores may reflect, to some extent, the way that parents answered the questions rather than an actual high proportion of infants with potential developmental delays, since questionnaires were presented to parents as epidemiological research on children's activities and not as a screening tool (with no planned medical follow-up). This approach may lead parents to give more rigorous answers to questionnaires on child development. Moreover, we could not exclude that French parents may have greater expectations for their children, leading to more rigorous answers. In epidemiological studies, ASQ results might be used as a quantitative evaluation, for instance, in considering area mean scores or the number of failed areas. Such use of the ASQ should be explored in future research. 


\section{CONCLUSION}

In conclusion, use of the ASQ for research purposes in a large child cohort study appeared a promising perspective, with very good parent involvement. The ASQ is probably a valid tool with which to explore factors associated with child development, as it exhibited known links between child development and both birth and social characteristics. However, further French studies of a larger number of children are needed to understand differences observed in 12-month ASQ gross motor scores compared with US norms. Moreover, for research purposes, it would be very interesting to explore the possibility of analyzing the ASQ in new ways, especially using quantitative approaches in order to have richer descriptions of a study population and not merely the two categories used for screening (pass/no pass). 


\section{REFERENCES}

1. American Academy of Pediatrics, Council on Children With D, Section on Developmental Behavioral, Pediatrics, Bright Futures Steering C, Medical Home Initiatives for Children With Special Needs Project Advisory C. Identifying infants and young children with developmental disorders in the medical home: an algorithm for developmental surveillance and screening. Pediatrics. 2006 Jul;118(1):405-20.

2. Hix-Small H, Marks K, Squires J, Nickel R. Impact of implementing developmental screening at 12 and 24 months in a pediatric practice. Pediatrics. 2007 Aug;120(2):3819.

3. Drotar D, Stancin T, Dworkin PH, Sices L, Wood S. Selecting developmental surveillance and screening tools. Pediatr Rev. 2008 Oct;29(10):e52-8.

4. Marks K, Hix-Small H, Clark K, Newman J. Lowering developmental screening thresholds and raising quality improvement for preterm children. Pediatrics. 2009 Jun;123(6):1516-23.

5. Sices L, Stancin T, Kirchner L, Bauchner H. PEDS and ASQ developmental screening tests may not identify the same children. Pediatrics. 2009 Oct;124(4):e640-7.

6. Bricker D, Squires J. Questionnaires sur les étapes du développement - Evaluation de l'enfant par les parents 2ème édition-a translation of the Ages and Stages Questionnaires - translated and adapted by Bonin M, Robaey P, Vandaele S, Bastin G-L, Lacroix V. Baltimore: Paul H. Brookes Publishing Co.; 2000.

7. Squires J, Potter L, Bricker D. The ASQ user's guide for the Ages and Stages Questionnaires: a parent-completed child monitoring system (2nd ed.). Paul Baltimore: Brookes Publishing; 1999. 
8. Bricker D, Squires J, Kaminski R, Mounts L. The validity, reliability, and cost of a parent-completed questionnaire system to evaluate at-risk infants. J Pediatr Psychol. 1988 Mar;13(1):55-68.

9. Skellern CY, Rogers Y, O'Callaghan MJ. A parent-completed developmental questionnaire: follow up of ex-premature infants. J Paediatr Child Health. 2001 Apr;37(2):125-9.

10. Heo KH, Squires J, Yovanoff P. Cross-cultural adaptation of a pre-school screening instrument: comparison of Korean and US populations. J Intellect Disabil Res. 2008 Mar;52(Pt 3):195-206.

11. Elbers J, Macnab A, McLeod E, Gagnon F. The Ages and Stages Questionnaires: feasibility of use as a screening tool for children in Canada. Can J Rural Med. 2008 Winter;13(1):9-14.

12. Kerstjens JM, Bos AF, ten Vergert EM, de Meer G, Butcher PR, Reijneveld SA. Support for the global feasibility of the Ages and Stages Questionnaire as developmental screener. Early Hum Dev. 2009 Jul;85(7):443-7.

13. Troude P, L'Helias LF, Raison-Boulley AM, Castel C, Bouyer J, de La Rochebrochard E. Apgar scores reported in personal child health records: validity for epidemiological studies? J Paediatr Child Health. 2008 Nov;44(11):665-9.

14. van Praag B. The perception of income inequality. European Economic Review. 1977;10:189-207.

15. Easterlin RA. Explaining happiness. Proc Natl Acad Sci U S A. 2003 Sep 16;100(19):11176-83.

16. Rydz D, Srour M, Oskoui M, Marget N, Shiller M, Birnbaum R, et al. Screening for developmental delay in the setting of a community pediatric clinic: a prospective assessment of parent-report questionnaires. Pediatrics. 2006 Oct;118(4):e1178-86. 
17. Blondel B, Supernant K., Du Mazaubrun C., Bréat G. Enquête périnatale 2003: situation en 2003 et évolution depuis 1998. DGS. [Rapport]. 2003.

18. Klamer A, Lando A, Pinborg A, Greisen G. Ages and Stages Questionnaire used to measure cognitive deficit in children born extremely preterm. Acta Paediatr. 2005 Sep;94(9):1327-9.

19. Plomgaard AM, Hansen BM, Greisen G. Measuring developmental deficit in children born at gestational age less than 26 weeks using a parent-completed developmental questionnaire. Acta Paediatr. 2006 Nov;95(11):1488-94.

20. Richter J, Janson H. A validation study of the Norwegian version of the Ages and Stages Questionnaires. Acta Paediatr. 2007 May;96(5):748-52.

21. Tong S, Baghurst P, Vimpani G, McMichael A. Socioeconomic position, maternal IQ, home environment, and cognitive development. J Pediatr. 2007 Sep;151(3):284-8, 8 e1.

22. Hillemeier MM, Farkas G, Morgan PL, Martin MA, Maczuga SA. Disparities in the prevalence of cognitive delay: how early do they appear? Paediatr Perinat Epidemiol. 2009 May;23(3):186-98.

23. Ment LR, Vohr B, Allan W, Katz KH, Schneider KC, Westerveld M, et al. Change in cognitive function over time in very low-birth-weight infants. JAMA. 2003 Feb $12 ; 289(6): 705-11$.

24. Janson H, Squires J. Parent-completed developmental screening in a Norwegian population sample: a comparison with US normative data. Acta Paediatr. 2004 Nov;93(11):1525-9.

25. Squires J, Twombly E, Bricker D, Potter L. ASQ-3 ${ }^{\mathrm{TM}}$ User's Guide. Baltimore: Paul H. Brookes Publishing Co.; 2009. 
26. Hindley CB, Filliozat AM, Klackenberg G, Nicolet-Meister D, Sand EA. Differences in age of walking in five European longitudinal samples. Hum Biol. 1966 Dec;38(4):36479.

27. WHO Motor Development Study: windows of achievement for six gross motor development milestones. Acta Paediatr Suppl. 2006 Apr;450:86-95.

28. Kelly Y, Sacker A, Schoon I, Nazroo J. Ethnic differences in achievement of developmental milestones by 9 months of age: The Millennium Cohort Study. Dev Med Child Neurol. 2006 Oct;48(10):825-30.

29. Lansdown RG, Goldstein H, Shah PM, Orley JH, Di G, Kaul KK, et al. Culturally appropriate measures for monitoring child development at family and community level: a WHO collaborative study. Bull World Health Organ. 1996;74(3):283-90.

30. Wu YT, Tsou KI, Hsu CH, Fang LJ, Yao G, Jeng SF. Brief report: Taiwanese infants' mental and motor development--6-24 months. J Pediatr Psychol. 2008 JanFeb;33(1):102-8. 
Figure 1. Study flowchart

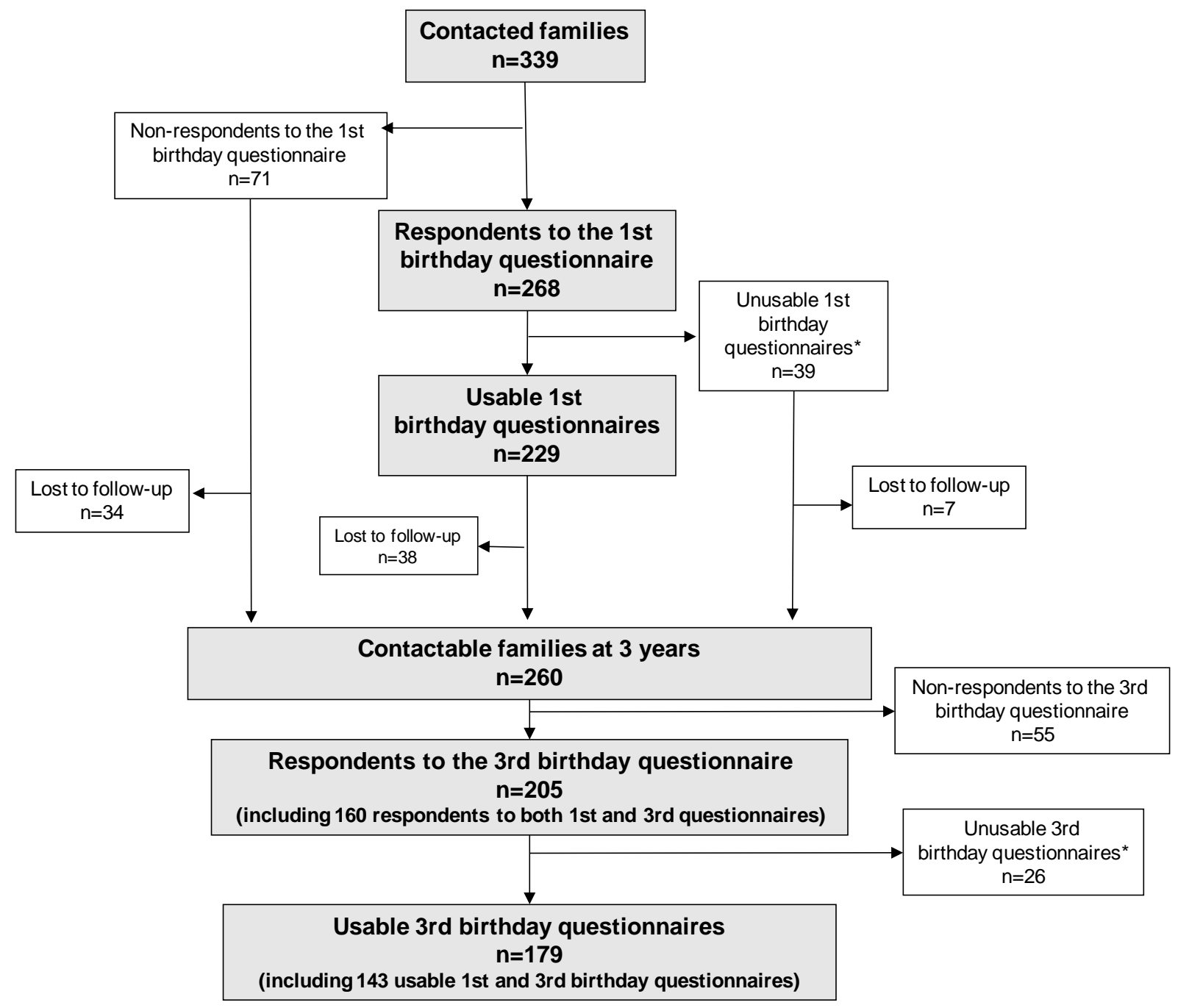

* Unusable questionnaires were due principally to delay in response leading to the child falling outside the "age window" for valid scoring (74\%) or to missing data on the child's exact age (14\%) 
Table 1. Study population characteristics $(n=265)$

n $\quad \% \quad$ Median [Q1-Q3]

\section{Children's characteristics}

Sex

Boy

Girl

Birth weight (g)

$<2500 \mathrm{~g}$

$\geq 2500 \mathrm{~g}$

Gestational age (WA)

$<37 \mathrm{WA}$

$\geq 37 \mathrm{WA}$

Newborn transferred to neonatology unit

No

Yes
$143 \quad 54$

$122 \quad 46$

$22 \quad 8$

$243 \quad 92$

259

$240 \quad 91$

$233 \quad 88$

$32 \quad 12$

\section{Parents' characteristics}

Maternal age at birth (yr)

$<35$

195

32 [29-35]

$\geq 35$

$70 \quad 26$

Paternal age at birth (yr)

$<35$

$167 \quad 64$

$\geq 35$

$93 \quad 36$

Parents' nationality

French

Other

$249 \quad 94$

$15 \quad 6$

Mother's educational level

$\leq 2$ years after high school diploma

$106 \quad 40$

$>2$ years after high school diploma

$157 \quad 60$

Father's educational level

$\leq 2$ years after high school diploma

$129 \quad 49$

$>2$ years after high school diploma

$132 \quad 51$

Perception of financial situation comfortable

fair

$44 \quad 23$

$94 \quad 48$

precarious

$46 \quad 24$

difficult or very difficult

$10 \quad 5$

Mother smoked during pregnancy

Yes

$32 \quad 12$

No

$233 \quad 88$

Mother working at the child's 1st birthday

No

Yes

$\begin{array}{ll}78 & 30\end{array}$

$186 \quad 70$

Mother working at the child's $3^{\text {rd }}$ birthday

No

$41 \quad 21$

Yes

$153 \quad 79$


Table 2. Results of the 12 and 36-month ASQs

\begin{tabular}{|c|c|c|c|c|c|c|}
\hline \multirow[b]{2}{*}{ ASQ } & \multirow[b]{2}{*}{ Areas } & \multicolumn{2}{|c|}{ Reference values * } & \multicolumn{2}{|c|}{$\begin{array}{c}\text { Results of the present } \\
\text { study }\end{array}$} & \multirow{2}{*}{$\begin{array}{c}\text { Difference of } \\
\text { mean } \\
\text { Scores } \\
{[95 \% \mathrm{CI}]^{\ddagger}}\end{array}$} \\
\hline & & $\begin{array}{l}\text { Cut- } \\
\text { off }\end{array}$ & $\begin{array}{l}\text { Mean scores } \\
\text { (SD) }\end{array}$ & $\begin{array}{c}\text { n }(\%) \\
\text { fail }\end{array}$ & $\begin{array}{l}\text { Mean scores } \\
\text { (SD) }\end{array}$ & \\
\hline \multirow{5}{*}{ 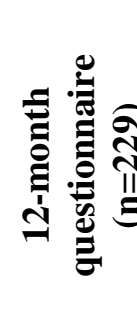 } & communication & 15.8 & $42.1(13.3)$ & $41(17.9)$ & $33.2(14.6)^{\S}$ & $8.9[7.0 ; 10.8]$ \\
\hline & gross motor & 18.0 & $48.6(15.3)$ & $61(26.6)$ & $34.1(21.3)^{\S}$ & $14.5[11.7 ; 17.3]$ \\
\hline & fine motor & 28.4 & $49.3(10.3)$ & $12(5.2)$ & $47.3(10.9)^{\S}$ & $2.0[0.5 ; 3.4]$ \\
\hline & problem solving & 25.2 & $48.5(11.7)$ & $29(12.7)$ & $43.1(13.2)^{\S}$ & $5.4[3.7 ; 7.2]$ \\
\hline & personal-social & 20.1 & $45.4(12.9)$ & $17(7.4)$ & $39.7(12.3)^{\S}$ & $5.7[4.1 ; 7.3]$ \\
\hline \multirow{5}{*}{ 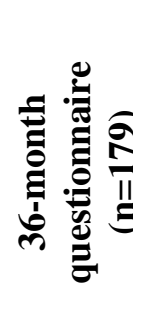 } & communication & 38.7 & $54.3(7.8)$ & $7(3.9)$ & $54.5(8.8)$ & $-0.2[-1.5 ; 1.1]$ \\
\hline & gross motor & 35.7 & $54.7(9.5)$ & $8(4.5)$ & $54.4(9.2)$ & $0.3[-1.1 ; 1.6]$ \\
\hline & fine motor & 30.0 & $52.1(11.1)$ & $21(11.7)$ & $46.2(14.4)^{\S}$ & $5.9[3.8 ; 8.1]$ \\
\hline & problem solving & 38.6 & $54.9(8.2)$ & $11(6.2)$ & $51.9(9.6)^{\S}$ & $3.0[1.5 ; 4.4]$ \\
\hline & personal-social & 38.7 & $53.4(7.4)$ & $12(6.7)$ & $50.6(9.2)^{\S}$ & $2.8[1.5 ; 4.2]$ \\
\hline
\end{tabular}

* Squires J, Potter L, Bricker D. The ASQ User's Guide for the Ages and Stages Questionnaires: A Parent-Completed, Child-Monitoring System. 2nd ed. Baltimore: Paul H. Brookes Publishing Co.; 1999.

$\dagger$ An area was considered as failed when the score was below the reference cut-off.

\$ reference mean score - study mean score

$\S \mathrm{p}$ Student's $\mathrm{t}$ test for mean scores comparison $<0.01$ 
Table 3. Factors associated with 12-month and 36-month ASQ results (univariate analysis)

\begin{tabular}{ccc}
\hline & 12-month ASQ \\
\hline Passed & $\begin{array}{c}\text { Failed } \\
(\mathrm{n}=197)\end{array}$ & \\
\hline $\mathrm{n}(\%)$ & $\mathrm{n}(\%)$ & $\begin{array}{c}\text { univariate } \\
\text { OR }[95 \% \mathrm{CI}]\end{array}$ \\
\hline
\end{tabular}

\begin{tabular}{ccc}
\multicolumn{3}{c}{ 36-month ASQ } \\
\hline $\begin{array}{c}\text { Passed } \\
(\mathrm{n}=167)\end{array}$ & $\begin{array}{c}\text { Failed } \\
(\mathrm{n}=12)\end{array}$ & \\
\hline $\mathbf{n}(\%)$ & $\mathbf{n}(\%)$ & $\begin{array}{c}\text { univariate } \\
\text { OR [95\% CI }]\end{array}$ \\
\hline
\end{tabular}

\section{Children's characteristics}

\begin{tabular}{|c|c|c|c|c|c|c|}
\hline \multicolumn{7}{|l|}{ Sex } \\
\hline Boy & $106(53.8)$ & $21(65.6)$ & $1.6[0.8-3.6]$ & $88(52.7)$ & $7(58.3)$ & $1.3[0.4-4.1]$ \\
\hline \multicolumn{7}{|l|}{ Birth weight } \\
\hline$<2500 \mathrm{~g}$ & $13(6.6)$ & $5(15.6)$ & $2.6[0.9-7.9]$ & $15(9.0)$ & $1(8.3)$ & $0.9[0.1-7.6]$ \\
\hline \multicolumn{7}{|l|}{ Gestational age } \\
\hline$<37 \mathrm{WA}$ & $15(7.6)$ & $8(25.0)$ & $4.0[1.6-10.5]$ & $15(9.0)$ & $2(16.7)$ & $2.0[0.4-10.1]$ \\
\hline \multicolumn{7}{|c|}{ Newborn transferred to neonatology unit } \\
\hline Yes & $21(10.7)$ & $9(28.1)$ & $3.3[1.3-8.0]$ & $16(9.6)$ & $3(25.5)$ & $3.1[0.8-12.8]$ \\
\hline \multicolumn{7}{|c|}{ Parents' characteristics } \\
\hline \multicolumn{7}{|c|}{ Maternal age at birth } \\
\hline$\geq 35$ years & $50(25.4)$ & $8(25.0)$ & $1.0[0.4-2.3]$ & $47(28.1)$ & $2(16.7)$ & $0.5[0.1-2.4]$ \\
\hline \multicolumn{7}{|l|}{ Paternal age at birth } \\
\hline$\geq 35$ years & $63(32.8)$ & $12(37.5)$ & $1.2[0.6-2.7]$ & $62(37.6)$ & $5(41.7)$ & $1.2[0.4-3.9]$ \\
\hline \multicolumn{7}{|l|}{ Parents' nationality } \\
\hline \multicolumn{7}{|c|}{ Mother's educational level } \\
\hline $\begin{array}{l}>2 \text { years after high } \\
\text { school diploma }\end{array}$ & $116(59.5)$ & $16(50.0)$ & $0.7[0.3-1.4]$ & $106(63.9)$ & $4(33.3)$ & $0.3[0.1-1.0]$ \\
\hline $\begin{array}{l}\text { Father's educations } \\
>2 \text { years after high } \\
\text { school diploma }\end{array}$ & $100(51.3)$ & $50(50.0)$ & $0.9[0.4-2.0]$ & $91(55.1)$ & $4(33.3)$ & $0.4[0.1-1.4]$ \\
\hline \multicolumn{7}{|c|}{ Mother smoked during pregnancy } \\
\hline Yes & $19(14.7)$ & $3(9.4)$ & $0.6[0.2-2.1]$ & $15(9.0)$ & $5(25.0)$ & $3.4[0.8-13.8]$ \\
\hline \multicolumn{7}{|c|}{ Mother working at the child's $1^{\text {st }}$ or $3^{\text {rd }}$ birthday } \\
\hline No & $60(30.6)$ & $11(34.4)$ & $1.2[0.5-2.6]$ & $36(21.7)$ & $4(36.4)$ & $2.1[0.6-7.4]$ \\
\hline \multicolumn{7}{|l|}{ Parents separated } \\
\hline Yes & $9(4.6)$ & $3(9.4)$ & $2.2[0.6-8.5]$ & $7(4.2)$ & $2(16.7)$ & $4.6[0.8-24.9]$ \\
\hline
\end{tabular}

* ASQ was considered as failed if scores of at least two areas were below the reference cut-off. 